\title{
CIÊNCIAS E HUMANIDADES: A GENTE SE ENCONTRA NO PÁTIO
}

\author{
Angelita Pereira de Lima ${ }^{1}$, Norton Gomes de Almeida ${ }^{2}$
}

\begin{abstract}
Resumo: Neste artigo, tomamos o pátio como metáfora poética, como palco de ações de extensão e como ingrediente espacial da relação entre áreas de conhecimento que foram separadas pelo modus operandi da própria ciência: isolar para conhecer. As práticas de extensão, conforme Paulo Freire, apontam para o contrário: a prática extensionista só é possível no diálogo e na comunicação. Nesse sentido, o pátio cumpre função simbólica na variável cultural de constituição da paisagem urbana e, no nosso caso, na paisagem do espaço acadêmico. Por isso, apresentamos as atividades práticas de extensão realizadas no Pátio da Ciência, organizadas pelo Instituto de Física, partindo do pressuposto de que não são conhecidas pelos ocupantes do vizinho Pátio Humanidades. Estabelecemos sua relação temporal/histórica e espacial. A aproximação dessas experiências foi propiciada por meio das Caex - Coordenações de Ações de Extensão das Unidades Acadêmicas que gravitam em torno do Pátio Humanidades, com seus projetos de extensão articulados no Programa Topofilias.
\end{abstract}

Palavras-chave: Extensão universitária. Pátio Humanidades. Pátio das Ciências. Comunicação e extensão.

SCIENCE AND HUMANITIES: WE MEET AT THE COURTYARD

Abstract: In this paper we take the courtyard as a poetic metaphor, as a stage of extension actions and as a spatial component of the relationship between areas of knowledge that were separated by the modus operandi of science itself: isolate to know. Extension practices, according to Paulo Freire, point to the opposite: extensionist practice is only possible in dialogue and communication. In this sense, the courtyard fulfills a symbolic function in the cultural variable of constitution of the urban

1 FIC/UFG - angelitalimaufg@gmail.com

2 IF/UFG - norton@ufg.br 
landscape and, in our case, in the landscape of the academic space. That being said, we present the practical extension activities carried out in the Pátio da Ciência, organized by the Institute of Physics, assuming that they are not known by the occupants of the neighboring Pátio Humanidades. We establish their temporal/historical and spatial relationship. The meeting of these experiences was provided through the several Caex - Extension Coordination of the Academic Units that revolve around Pátio Humanidades, with their extension projects articulated in the Topofilias Program.

Keywords: University Extension. Courtyard of Humanities. Courtyard of Sciences. Communication and extension.

\section{CIENCIAS Y HUMANIDADES: NOS ENCONTRAMOS EN EL PATIO}

Resúmen: En este artículo tomamos el patio como metáfora poética, como escenario de acciones de extensión y como el ingrediente espacial de la relación entre áreas de conocimiento que se separaran por el modus operandi de la propia ciencia: aislar para conocer. Las prácticas de extensión, según Paulo Freire, apuntan a lo contrario: la práctica extensionista sólo es posible en el diálogo y en la comunicación. En este sentido, el patio cumple función simbólica en la variable cultural de constitución del paisaje urbano y, en nuestro caso, en el paisaje del espacio académico. Por eso, presentamos las actividades prácticas de extensión realizadas en el Patio de la Ciencia, organizadas por el Instituto de Física, partiendo del supuesto que no son conocidas por los ocupantes del vecino patio Humanidades. Establecimos su relación temporal / histórica y espacial. La aproximación de estas experiencias fue propiciada por medio de las Caex - Coordinaciones de Acciones de Extensión de las Unidades Académicas que gravitan en torno al Patio Humanidades, con sus proyectos de extensión articulados en el Programa Topofilias.

Palabras clave: Extensión universitaria. Patio de las Humanidades. Patio de las Ciencias. Comunicación y extensión.

O sujeito pensante não pode pensar sozinho; não pode pensar sem a co-participação de outros sujeitos no ato de pensar sobre o objeto. Não há um "penso", mas "pensamos". É o "pensamos" que estabelece o "penso" e não o contrário. Esta co-participação dos sujeitos no ato de pensar se dá na comunicação. (FREIRE, 2006, p. 66)

\section{TÃO PERTO, TÃO LONGE}

Na definição dicionarizada (Aurélio, 1986), um dos significados conferidos ao termo pátio é palco, teatro aberto. Remete a um espaço para encenação 
pública, para a representação e para criação. Embora tenha sido concebido na arquitetura como espaço funcional para interligar ambientes, garantindo iluminação e ventilação, adotamos aqui a ideia de que o pátio cumpre função simbólica na variável cultural de constituição da paisagem urbana e, no nosso caso, na paisagem do espaço acadêmico.

\footnotetext{
Os referentes da cultura associados à questão da paisagem permitem reconhecer nas dualidades do espaço pátio - aberto e fechado, público e privado, edifício e cidade - modos do homem se organizar espacialmente, que pressupõem o abandono da natureza e sua transfiguração em paisagem. (DIAS e CAMPOS, 2012).
}

Ao carregar na sua forma a dualidade, a existência do espaço pátio aponta para a intensidade de convivência dialética, conflituosa e, também, pujante, sobretudo nos pátios de edifícios de função pública como nas universidades. Dessa forma, podemos chegar, também, a uma função poética deste espaço: pátio é lugar de passagem, de permanência efêmera, porém contínua. Ao mesmo tempo, respira ares de resistência simbólica, cultural e transpira memórias.

O nosso pátio em questão separa e interliga, ambiguamente, as ciências humanas das ciências exatas. Neste artigo, tomamos o pátio como metáfora poética, como palco de ações de extensão e como ingrediente espacial da relação entre áreas de conhecimento que foram seccionadas pelo modus operandi da própria ciência: isolar para conhecer. Portanto, é emblemático que o mesmo pátio que separa a Física das Humanidades seja o elemento articulador desse encontro. E, nesse dossiê, o articulador temático de projetos de extensão.

Neste artigo objetivamos apresentar uma relação temporal/histórica e espacial no Pátio Humanidades e sua possível relação com o Pátio da Ciência. $\mathrm{Na}$ atual conjuntura, uma aproximação dessas experiências foi propiciada por meio das Caex - Coordenações de Ações de Extensão das Unidades Acadêmicas que gravitam em torno do Pátio Humanidades, com seus projetos de extensão articulados no Programa Topofilias. No nosso caso, a Faculdade de Informação e Comunicação (FIC) e o Instituto de Física (IF), vizinhas de Pátio, porém de costas uma para a outra, participam do Programa e tentam superar a distância gerada por rupturas epistemológicas e produzir outras conexões entre os saberes a partir da extensão universitária. 


\section{Extensão e conexões de saberes}

A extensão universitária é um das pontas do "tripé" ensino, pesquisa e extensão, mas historicamente foi relegada a um plano de menor atenção pela maioria dos cursos e dos gestores das universidades. Hoje a realidade é um pouco diferente: há políticas de reconhecimento acadêmico e administrativo para quem desenvolve projetos de extensão, embora com menor valor simbólico. A universidade brasileira ainda dispensa maior atenção, valor simbólico e financiamento à pesquisa e ao ensino. Mas a extensão sempre teve seu lugar ao sol. E, atualmente, na qualidade da extensão que se realiza reside esperança de se estabelecer um diálogo mais profícuo entre a universidade e a sociedade - um externo/interno que a habita. Necessidade absoluta para enfrentar as políticas e os comandos de enfraquecimento do ensino superior, e, sobretudo, das universidades públicas.

O Plano Nacional de Educação - PNE - determina as diretrizes, metas e estratégias para a política educacional brasileira no período de 2014 a 2024, Lei 13.005/2014 (BRASIL, 2018), e prevê em sua meta 12 a elevação de 50\% da taxa bruta da população entre 18 e 24 anos no ensino superior. Para alcançar essa meta, uma das estratégias estabelecidas é a 12.7 que recomenda "assegurar, no mínimo, $10 \%$ (dez por cento) do total de créditos curriculares exigidos para a graduação em programas e projetos de extensão universitária, orientando sua ação, prioritariamente, para áreas de grande pertinência social”. (BRASIL, PNE, 2014). O PNE reconhece a força da extensão universitária junto às demandas sociais, justamente por seu potencial de diálogo com a sociedade e aponta para necessidade de mudança curricular nas universidades.

Hoje, pode-se dizer, portanto, que a extensão é menina dos olhos para a visibilidade das ações universitárias e para a distribuição do conhecimento produzido por meio de pesquisas nas universidades brasileiras. No entanto, ainda não há uma garantia de que ela seja praticada de modo a estabelecer uma relação respeitosa, inclusiva e dialógica com a população externa à universidade. Já vai pra meio século que Paulo Freire problematizou o termo extensão, desmontando o caráter autoritário e invasivo de ações de extensão junto a populações de periferia urbana e rural. Para Freire (2006) a extensão bem sucedida é um processo de comunicação, estabelece diálogos e trocas de saberes.

A comunicação (...) implica uma reciprocidade que não pode ser rompida. Por isto, não é possível compreender o pensamento fora de sua dupla função: cognoscitiva e comunicativa 
(...) Desta forma, na comunicação não há sujeitos passivos. Os sujeitos cointencionados ao objeto de seu pensar se comunicam seu conteúdo. (FREIRE, 2006, p. 67)

A advertência de Paulo Freire é tão válida para os tempos atuais, quanto foi para o momento em que criticou o modelo autoritário extensionista dos anos 1970: “A educação é comunicação, é diálogo, na medida em que não é a transferência de saber, mas um encontro de sujeitos interlocutores que buscam a significação dos significados" (FREIRE, 2006, p. 69).

No curso de jornalismo da UFG, embalado pelas Diretrizes Curriculares Nacionais de 2013 e pela tramitação do PNE no Congresso Nacional, houve a curricularização da extensão. O objetivo é preparar academicamente estudantes e professores para as ações de extensão. Pois, uma coisa é certa: não se faz pesquisa sem estudar metodologia de pesquisa. Portanto, não se deveria fazer "extensão" sem compreender o campo de conhecimento que embasa a prática de extensão, as disputas conceituais e políticas que permeia essa prática universitária.

Por causa de seu potencial de impactar a realidade que a extensão foi o campo escolhido para contribuir com a revitalização do Pátio Humanidades, recentemente ocupada por conflitos, violências e tráfico. Nesse sentido, o encontro das Humanidades com a Física tem, também, essa função de ressignificar os usos do espaço pátio na Universidade Federal de Goiás e, mais especificamente, no pátio entre a FIC e o IF por meio das ações de extensão. Dentre essas atividades, talvez seja interessante ressaltar que, pelas suas características, o projeto Pátio da Ciência é o que mais se aproxima do projeto a ser desenvolvido no Pátio Humanidades, proporcionando uma boa reflexão sobre se ele deve seguir a linha do que é feito no Pátio da Ciência ou não (lembrando que os quatro estandes do Pátio da Ciência são permanentes). A prática de extensão no Instituto de Física da Universidade Federal de Goiás é pujante e tem uma pegada inovadora.

\section{O encontro da Física com as Humanidades Pela extensão}

Para quem se posiciona no Pátio Humanidades de frente para o bosque Saint Hilaire, no Campus Samambaia da UFG, à sua esquerda encontra o edifício do Instituto de Física, que à sua esquerda, abriga outro pátio, o da Ciência. Os pátios Humanidades e da Ciência estão posicionados paralelamente e separados apenas pelo prédio do IF. Tão perto e tão longe. A comunidade 
acadêmica que frequenta o lado do pátio Humanidades mal sabe o que se passa do outro lado e vice-versa.

Estamos ali, vizinhos, juntos, desde quando ainda havia o Instituto de Matemática e Física, nos anos 1970. Hoje, um está de costas para o outro. Houve uma época que não: matemática, física, informática se encontravam nas escadas do antigo ICHL. Dessa convivência surgiram muitos relacionamentos e parcerias. A formação de chapas para o DCE nos anos 1980, debates interdisciplinares e formulações políticas nos centros acadêmicos. Aparentemente, a efervescência se dava do lado de cá, nas Humanidades. Mas, as história mostra que do lado de lá também tem uma pujança histórica. Mas há uma desconfiança de que essas histórias não sejam tão conhecidas.

\section{Semana de Física}

Talvez não seja de conhecimento da comunidade acadêmica, mas as atividades de extensão no IF existem desde o período de criação do Instituto. A atividade mais antiga de extensão no IF é a já tradicional Semana da Física (SF), que ocorre ininterruptamente há 34 anos. Sua história nos reporta ao segundo semestre de 1984, quando foi iniciada a implantação de uma nova organização dos cursos de graduação da UFG em Regime Seriado Anual.

Entretanto, a greve geral dos docentes, iniciada em maio daquele ano e só encerrada em fins de agosto, impediu que a nova organização dos cursos e suas implicações para a vida acadêmica dos estudantes fossem devidamente esclarecidas. Em vista disso e do descontentamento com a situação, foi acatada uma proposta apresentada pelos professores Orlando Afonso Valle do Amaral, Nelson Cardoso Amaral e de alunos de física ligados ao Centro Acadêmico de Física. Dessa mobilização, surgiu, em novembro de 1984, a "Semana de Debates da Física".

Os debates realizados nos dias 27 a 29 de novembro trataram da situação e perspectivas do Departamento de Física; avaliaram as implicações do regime seriado anual sobre a estrutura dos cursos de Licenciatura e Bacharelado em Física e as atividades acadêmicas dos alunos dos cursos. De acordo com o professor Fernando Pelegrini, ex-diretor do IF, os temas abordados no ano de 1984 foram:

Dia 27 - 9:30 - 11:00 horas. A estrutura do Departamento de Física (F. Pelegrini). A estrutura do Colegiado de Física (Ricardo Bufaiçal). Representação estudantil (Elze Pinheiro). Ensino de $1^{\circ}$ e $2^{\circ}$ Graus (Itamar). Regime de créditos e regime seriado anual (Ricardo Bufaiçal). Dia 28 - 8:00 - 10:00 horas. Ensino e pesquisa no Departamento de 
Física (Walmir Guedes). A formação do profissional (Antônio Pélico). Problemas atuais do curso de Física (Gilberto) - Dia 29 - 8:00 - 11:00. Continuação dos debates dos dias anteriores. Participantes: 32 alunos (41 matriculados) e 10 Professores (corpo docente 31). Propostas aprovadas: 1: Aulas de reforço para os alunos ao longo do ano. 2: Horário vago para atividades acadêmicas. 3: Criar uma coordenação para cada ano dos cursos. 4: Promover a Semana da Física no próximo ano, em setembro. (PELEGRINI, 2018)

De acordo com informações disponívieis no site do Instituto de Física (2018), foi a partir dessa reunião relatada pelo professor Pelegrini que se elaborou a proposta de criação da Semana de Física, como evento anual do curso. Em 1985, realizou-se a segunda Semana de Física e, em 1986, ela foi ampliada para a "Semana do Instituto de Matemática e Física", por iniciativa do rofessor Nelson Cardoso Amaral, então diretor do IMF. Esse evento foi realizado até 1996 e é considerado um dos pioneiros na UFG, tendo influenciado na criação de semanas de cursos de graduação em diferents Unidades Acadêmicas.

Em 1997 o IMF foi desmembrado em três institutos independentes, incluindo o Instituto de Física (IF), e, assim, a "Semana da Física” retornou à sua antiga denominação. No ano de 1997 deliberou-se por uma nova contagem, e teve-se então a "I Semana da Física". Com essa nova contagem, em 2002 teríamos a "VI Semana da Física". Entretanto, nesse ano a Comissão Organizadora, juntamente com o Conselho Diretor do IF, julgaram oportuno resgatar tradição criada pela "Semana da Física" de 1984, bem como seu histórico papel, passando a enumerá-la a partir daquele ano. Foi assim que, em 2002, foi realizada a "XIX Semana da Física".

É preciso ressaltar que, desde sua primeira edição em 1984, a SF mudou bastante. De fato, enquanto a primeira edição contou com cerca de 30 participantes, hoje mais de 300 pessoas participam desse evento, incluindo aí os pesquisadores e alunos de graduação e de pós-graduação de várias unidades da UFG e de outras instituições bem como alunos e professores de escolas públicas e privadas do ensino médio. Contribuem para a SF pesquisadores do IF-UFG e também de outras instituições que ministram não só palestras de divulgação com os mais recentes avanços da área de atuação, mas também ministram minicursos, participam de mesas redondas e seminários. Além disso, durante a SF os laboratórios são abertos para visitação, além de contar com o apoio de outros projetos de extensão que se integram à SF, como por exemplo o Pátio da Ciência e o Clube de Astronomia Cecília Payne - CACP, sobre os quais iremos falar mais adiante. 
CARTAZ de divulgação - 2018

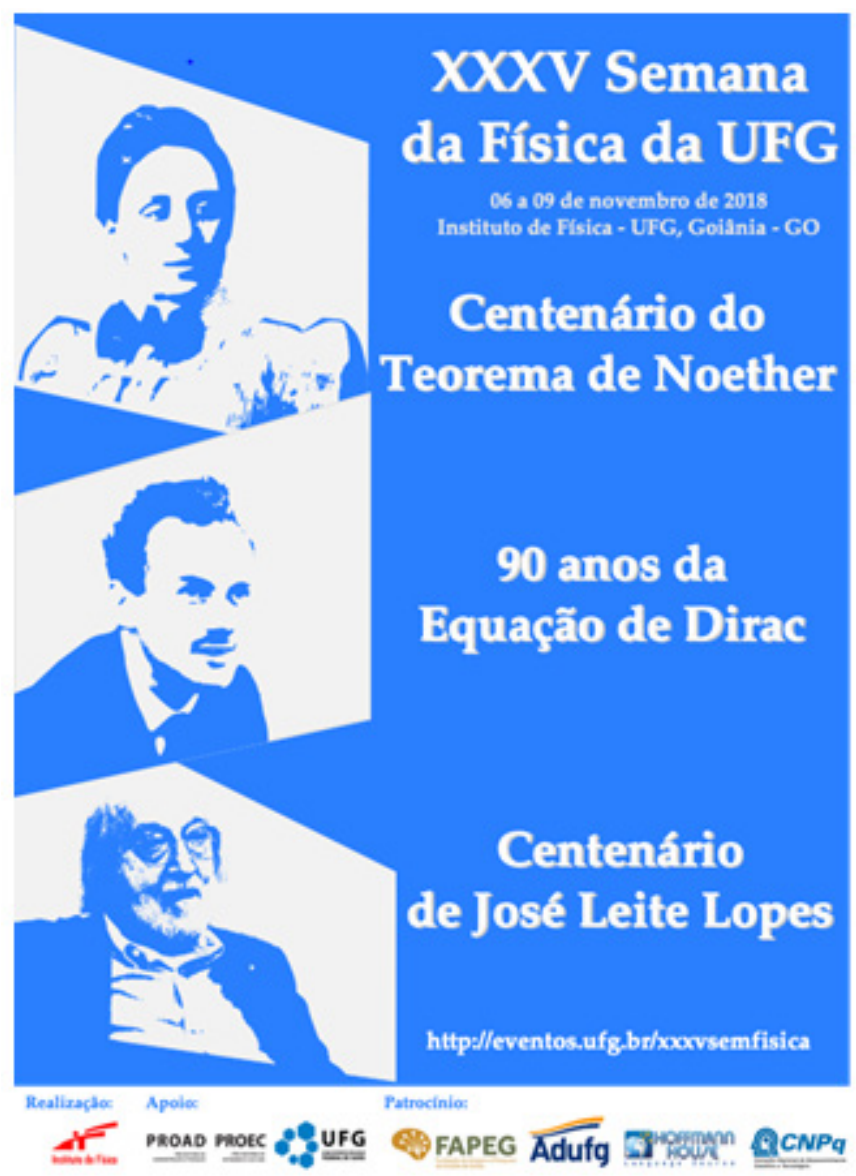

FONTE: ACERVo IF-ACESSÍVEL EM: HTTPS://WWW.IF.UFG.BR/

\section{Olimpíada de Física}

Outra importante atividade de extensão é a Olimpíada Brasileira de Física (OBF), que começou em 1999. Desde o início, o estado de Goiás participa desse projeto, e mais recentemente foi criada a Olimpíada Brasileira de Física das Escolas Públicas (OBFEP). A OBF tem por objetivo valorizar a escola pública, melhorar o ensino e promover o ensino de ciências em geral, particularmente o ensino de física. Além disso, essa olimpíada visa ampliar a colaboração entre as escolas e centros de pesquisa, como universidades e sociedades científicas (MARTINS, 2018). O projeto piloto da OBFEP foi implementado em 2010 e o estado de Goiás estava já participando juntamente com a Bahia, Piauí e São Paulo. Para se ter uma ideia da importância desse projeto, hoje as duas olimpíadas têm coordenações estaduais em todos os estados, inclusive no DF. 


\section{Escola de Física}

Outra atividade de extensão do IF voltado para escolas da região metropolitana é a Escola de Física, que surgiu de uma discussão no Conselho Diretor de como atrair mais estudantes para o IF. De acordo com o professor Salviano Leão, a primeira Escola de Física foi realizada no ano de 2008. Naquele ano, excepcionalmente, houve a participação de 450 alunos. Esse número hoje se estabilizou em cerca de cerca de 200 alunos. O que explica a expressiva participação na primeira edição, na sua opinião, é o fato de que muitos alunos participaram com a expectativa de que seriam dadas "dicas" para o vestibular. A Escola de Física tem por objetivo promover interação entre o Instituto de Física e os alunos e professores do Ensino Médio, discutir temas que sejam de interesse de formação desses estudantes, divulgar o trabalho de pesquisa realizado no IF-UFG para a comunidade e atrair alunos interessados nos cursos de graduação oferecidos pelo IF. A Escola de Física conta com palestras de apresentação dos cursos de graduação, visitas a laboratórios de demonstração, visitas a laboratórios de ensino e de pesquisa, visita ao Planetário-UFG, sessão de cinema e palestras sobre temas da física contemporânea.

\section{Pátio da Ciência}

O Pátio da Ciência, outro importante projeto de extensão, foi criado em 2009 e teve como proponentes os professores Jesiel Freitas Carvalho, Paulo Celso Ferrari, Luiz Gonzaga Roversi Genovesi, Lauro June Queiroz Maia, Carlito Lariucci e Ricardo Avelino Gomes. O Pátio da Ciência é uma iniciativa de divulgação científica dos Institutos de Física e de Química da Universidade Federal de Goiás (CARVALHO, 2009) para proporcionar um ambiente de educação científica não-formal à comunidade em geral, em especial aos estudantes do ensino fundamental e médio. O Pátio da Ciência está localizado entre o Instituto de Física e o Instituto de Química, no Câmpus Samambaia, e conta com um auditório para cerca de 60 pessoas. $\mathrm{O}$ atendimento ao público é feito por monitores, e os visitantes têm a oportunidade de ver, se informar e interagir com os experimentos de Física e Química. Desde sua inauguração, em 19 de novembro de 2012, já atendeu mais de 1.200 alunos de cerca de 20 escolas do município de Goiânia. Seus quatro amplos estandes ficam abertos durante eventos realizados na UFG, como a Semana da Física, a Olimpíada Brasileira de Física, o Espaço das Profissões, a Semana Nacional de Ciência e Tecnologia e a Escola de Física. 
Em 2014, um estudo foi realizado por um estudante e professores do IF (PINTO, 2014) com três objetivos: investigar as impressões dos visitantes, investigar se os objetivos do Pátio da Ciência estão sendo cumpridos e se o Pátio da Ciência pode ser considerado um Centro de Ciências. Trata-se do primeiro estudo acadêmico sobre as atividades desse Pátio. Os investigadores concluíram que os estudantes que visitavam o Pátio avaliaram positivamente a atuação dos monitores responsáveis pela apresentação dos experimentos bem como a organização do Pátio, e até reivindicaram a ampliação do número de estandes e monitores. Além disso, concluíram que o Pátio da Ciência mesmo não cumprindo todos os objetivos, pode ser considerado um Centro de Ciências.

\section{IYPT-B}

O International Young Physicist's Tournament - Brasil (IYPT-B), que teve a iniciativa do Colégio Visão e é realizado em parceria com a UFG, é um outro projeto de extensão do IF que merece destaque. Embora professores do IF- UFG tenham auxiliado informalmente o IYPT-B desde 2013, esse projeto somente foi cadastrado em 2016. A equipe do IYPT na UFG é formada pelos professores Salviano Leão, atual coordenador, Giovani Piacente e Marcus Carrião dos Santos. O professor Elton Pita é o representante do Colégio Visão. O IYPT-B é uma competição científica para estudantes do Ensino Médio, a partir da qual é selecionada a equipe brasileira para o IYPT, o qual foi criado por professores do Departamento de Física da Universidade de Moscou, Rússia.

Em seu pouco tempo de duração, importantes resultados já foram obtidos. Dentre eles podemos destacar a conquista do quarto lugar nacional em 2015 com a equipe "Pequi de Newton". Nessa ocasião o aluno Thiago Kalife foi selecionado para a etapa Internacional na Tailândia. Em 2017, a equipe "Bósons do Cerrado" também conquistou o quarto lugar na competição nacional. Desta vez, o estudante Matheus Laureano foi o selecionado para compor a delegação brasileira que foi para Singapura, onde 29 países participaram da competição. De acordo com o professor Elton Pita, outros importantes resultados para os alunos envolvidos, decorrentes dessa iniciativa, são: auxílio no momento da escolha do curso superior; aumento na aprovação em vestibulares e cursos mais exigentes; aquisição de conhecimento técnico de manuseio de softwares da área de exatas; estabelecimento de networks com grupos de pesquisa de diferentes instituições e a possibilidade de adquirir experiência internacional e cursar universidades em outros países. 


\section{Clube de Astronomia}

Uma das atividades mais recentes de extensão do IF é o Clube de Astronomia Cecília Payne - CACP. Ele foi fundado no dia 02 de Março de 2015 por amantes da astronomia e do ensino de astronomia dentro do Instituto de Física da Universidade Federal de Goiás. O intuito é o de promover e divulgar astronomia através das redes sociais e, também, oferecendo sessões de observações astronômicas para o público em geral. Conforme o Clube foi atraindo mais pessoas para os eventos e também para a adesão como membros efetivos, novos projetos foram sendo realizados. Desde então, o Clube cresce e aumenta sua capacidade de levar a astronomia e suas vertentes para todos e de maneira acessível.

Como registro da primeira atividade do Clube, os membros fundadores, dentre eles os alunos de física Lucas Vieira Freitas e Richard Quintiliano Matos citam uma reunião realizada no anfiteatro do Instituto de Física, no ano de 2015, para divulgar o projeto, os objetivos e também para convidar para participação como membros alunos de outros cursos que tenham interesse em astronomia. Desde então, o Clube já realizou mais de 20 observações públicas nas dependências da UFG - muitas acompanhando fenômenos astronômicos. Também realizou centenas de eventos de popularização da ciência e astronomia, incluindo observações no Parque Municipal Vaca Brava no Dia Mundial da Observação Lunar, observações nos eventos Sábado Com Ciência, ocorridos anualmente, organização do Dia Nacional da Astronomia em 2018, em pareceria com o Planetário UFG, e também a organização da "I noite de Observação Astronômica na Cidade de Goiás", com apoio da FAPEG, por ocasião do "Dia C da Ciência".

Além disso, o Clube transmitiu várias vezes a série "Cosmos: Uma Odisseia no Espaço" e a série "Cosmos: Uma Viagem Pessoal" no Auditório do Pátio da Ciência da UFG. Foram construídos vários experimentos de baixo custo para demonstrar e simular fenômenos astronômicos e, também, demonstrar sua natureza como o Sistema Solar em escala de tamanho e de distância; foguetes de garrafa pet, com pára-quedas programado para abrir quando em queda; experimentos explicando as estações do ano, as fases da Lua e os eclipses; e experimento do tecido espaço-tempo para ensinar noções de gravitação universal, cosmologia e relatividade geral.

Esses experimentos foram apresentados em dezenas de escolas de ensino médio e fundamental, tanto pela rede pública quanto pela particular, inclusive 
em escolas do interior, como Ceres, Bela Vista e Goiás. Também são realizadas pequenas palestras explicativas sobre temas que estão sendo discutidos atualmente na comunidade astronômica ou sobre assuntos importantes para o entendimento da astronomia, com o intuito de informar e explicar o Universo a nossa volta de maneira didática, contribuindo assim para a divulgação científica no Estado de Goiás.

Paralelamente, o CACP, coordenado pelo professor Norton G. de Almeida, ensina e divulga conceitos de astronomia e ciência através das redes sociais. A página do Clube no Facebook, que já ultrapassou duas mil curtidas, é um dos recursos mais usados para a divulgação da astronomia. Ali são publicadas notícias, curiosidades, avistamentos de satélites, fenômenos astronômicos, os eventos realizados pelo Clube, além das astrofotografias feitas por membros e seguidores do Clube. O Instagram e o Youtube também são meios de divulgação usados pelo Clube.

\section{Café com Ciência}

A atividade mais recente de extensão do IF-UFG é o "Café com Ciência”, que começou no ano passado. Nessa atividade, palestrantes das mais diversas áreas do conhecimento falam para estudantes de graduação, professores, alunos da universidade e para a comunidade que queira participar. É preciso ressaltar que embora o convite se estenda à comunidade não universitária, o público frequente é formado pela comunidade acadêmica. De acordo com o Prof. Andris Figueiroa Bakuzis, idealizador do Café com Ciência, esse programa surgiu em 2017, ao observar que havia uma demanda de alunos e professores que buscavam atividades no horário das 13:00 às 14:00. Um dos objetivos do Café com Ciência é ter um momento para discutir as ideias de pesquisadores das mais diversas áreas do conhecimento, tanto para divulgar quanto para discutir temas avançados de pesquisa na área dos convidados, e de uma forma que seja compreensível aos participantes. O nome "café» é porque um café é servido durante o colóquio, para deixar o ambiente mais informal ou descontraído. Desde que foi criado, o Café com Ciência recebe semanalmente cerca de 140 pessoas no auditório do IF. Além de professores do Instituto de Física, palestrantes convidados de outros departamentos, de outras universidades e muitos palestrantes estrangeiros discutiram suas pesquisas no Café com Ciência. 


\section{Notas CONCLUSIVAS}

Com os relatos de experiências neste artigo objetivamos demonstrar a existência, a qualidade e potência das ações de extensão que são realizadas na UFG, mais especificamente no Instituto de Física. Desejamos, também, revelar a importância de se criar mecanismos para interconectar os mundos de extensão existentes e os mundos não concretizados ainda. Os espaços pátio são um desses potentes mecanismos. O Pátio da Ciência e o Pátio Humanidades são co-irmãos, vizinhos e semelhantes no potencial articulador das criatividades e afetividades que os circundam. Um tem muito a aprender com o outro. O desafio tem sido atravessar a barreira simbólica que separa os dois campos de saberes.

Se assim ocorre entre Unidades Acadêmicas vizinhas, certamente, a distância entre a Universidade e as comunidades externas também são dramáticas. Iniciativas inteligentes e comprometidas têm sido criadas pela comunidade acadêmica e pela gestão da UFG. No entanto, consideramos necessário aprofundar metodológica e conceitualmente a prática de extensão. E, também, avançar no seu financiamento. As metas do PNE para a extensão, conforme mencionado neste artigo, são um exemplo de demandas nas quais necessitamos focar, enquanto instituição comprometida com a inclusão e com o acesso à educação de qualidade e pública.

Paulo Freire vislumbrou o potencial de educação na prática de extensão participativa, o que para ele funciona como um processo comunicativo e não de extensão propriamente dito. Para estabelecer relações dialógicas entre o conhecimento acadêmico e os conhecimentos existentes fora dos requisitos científicos - mas que guardam em si a validade e a legitimidade dos saberes tradicionais e das tecnologias sociais desenvolvidas pela experiência do viver -, é necessário quebrar a prepotência do saber canônico quando ele se considera o único modo de conhecimento com rigor e validade.

A extensão universitária é uma ponte que interliga esses mundos e precisa ser de múltiplos fluxos e sentidos. Há um percurso longo e permanente nessa relação. A cada ano, centenas de estudantes deixam de frequentar os nossos pátios e seguem seus rumos para além dos campus universitários. Todo ano, outras centenas iniciam essa relação trazendo para o espaço pátio UFG outros mundos, às vezes invisíveis ao saber acadêmico. Quando esses saberes se encontram 
há energias e há potência. Precisamos compreendê-las, precisamos aprender com elas. Este artigo funciona como um pátio. Esse dossiê é um pátio

\section{REFERÊNCIAS}

BRASIL. Plano Nacional de Educação. Disponível em: $<$ http://pne.mec.gov.br/18-planos-subnacionais-de-educacao/543-plano-nacional-de-educacao-lei-n-13-005-2014>. Acessado em 28 de nov. de 2018.

CARVAlHO, J. F. et al. Pátio da Ciência - Um Centro de Ciências na UFG. Proposta submetida ao Edital CNPq/SECIS/MCT/Fundações Estaduais de Amparo à Pesquisa no 064/2009. Goiânia: Ministério da Ciência e Tecnologia/Conselho Nacional de Desenvolvimento Científico e Tecnológico, 2009.

DIAS, Fabiano Vieira; CAMPOS, Martha Machado. Pátios: espaços de introversão e captura da paisagem. Arquitetura e paisagem cultural. In: Colóquio Ibero-americano - Paisagem cultural, patrimônio e projeto. $2^{\circ}$, 2012, Belo Horizonte. Anais.

FREIRE, Paulo. Extensão ou comunicação? 13a ed. São Paulo:Paz e Terra, 2006.

MARTINS, Jefferson da Silva. Olimpíada brasileira de física nas escolas públicas. Disponível em: $<$ https://srefabricianodivep.wordpress.com/2016/04/11/olimpiada-brasileira-de-fisica-das-escolas-publicas/>. Acesso em 20 de nov.de 2018.

PELEGRINI, F. Sobre a Semana da Física da UFG. Goiânia: informações enviadas por email. Em 23 de nov. de 2018.

PINTO, Cássio Ramos, Queiroz, José Rildo, Ferrari, Paulo Celso. Pátio da Ciência da Universidade Federal de Goiás: um Centro de Ciências? XV Encontro de Pesquisa em Ensino de Física. Maresias, 2014.

NOVO AURÉLIO. O dicionário da Língua Portuguesa - Século XXI. São Paulo: Nova Fronteira, 1986.

Instituto de Física. Disponível em www.if.ufg.br, acessado em 30 de novembro de 2018.

Recebido em novembro de 2018

Aprovado em dezembro de 2018. 